\title{
TOUCHING base
}

\section{OForecasting The Microarray Meeting}

Its recent supplement having met with welcome reception, Nature Genetics will host an interdisciplinary forum to discuss the applications and challenges of microarray technology. Inspired by previous workshops hosted by Patrick Brown (of Stanford University) and Jeffrey Trent (of the National Human Genome Research Institute), the meeting will include presentations by those developing the technology, as well as those who are adapting it to address biological questions. Discussions, poster sessions, and a schedule and venue conducive to informal interaction are designed to appeal both to those who seek to better understand the potential of this technology, and those already wading knee-deep in data sets who need to keep abreast of current developments. The Microarray Meeting will be held on 22-25 September 1999, in Phoenix, Arizona.

\section{Pink ribbon yoghurts}

Yoghurt is good for your health, especially between now and 30 April 1999. For every pink Yoplait lid it receives from its customers, the company will donate $50 \not \subset$ to The Breast Cancer Research Foundation. Their guaranteed max imum donation is $\$ 100,000$ - keep popping those lids.

\section{Potassium channels put out}

DFNA2, one of the 19 loci for autosomal dominant deafness, has received exceptional coverage over the last few months. In December's issue of Nature Genetics, Jia-hui Xia and colleagues reported that mutations in a new connexin gene positioned at the DFNA2 locus give rise to non-syndromic deafness. In the current issue (see page 263), Guy Van Camp and colleagues posit that genetic heterogeneity applies, not only to deafness, but to the DFNA2 locus itselfalso supported by a report by Thomas Jentsch, Christine Petit and colleagues that appeared recently in Cell (96, 437-446, 1999). Jentsch and co-workers found that mutations in a new potassium channel gene (KCNQ4) whose chromosomal location also coincides with DFNA2 are responsible for non-syndromic dominant deafness. They went on to demonstrate expression of Kcnq4 in the outer sensory hair cells of the cochlea in the mouse, and that KCNQ4 forms heterodimers with another potassium channel protein, KCNQ3. While previous studies suggest that another potassium channel, KCNQ1 (and its 'sidekick', minK), may be involved in secreting potassium ions from the stria vascularis into the cochlear endolymph, the expression pattern of Kcnq4 argues that its activity is specific to the outer hair cells-where it may modulate excitability or the basolateral removal of potassium ions from them. Future studies will doubtless illuminate in this regard and also with respect to the polygenic nature of DFNA2. As Van Camp and colleagues point out, there appears to be at least one more DFNA2 gene that has yet to be discovered.
The yin and yang of prostate cancer?

Almost 200,000 new cases of prostate cancer were diagnosed last year in the United States alone, and despite improved treatment, prostate cancer remains the second leading cause of cancer death among men. One of the few discernable genetic alterations in prostate tumours is the expression of pp32,

a nuclear phosphoprotein. Paradoxically, pp32 is thought to act as a tumour suppressor. A report in this month's issue of Nature Medicine goes some way to resolving the PP32 conundrum (Nature Med. 5, 275-279, 1999). As it turns out, there are at least three members of the PP32 gene family, located on different chromosomes. And while PP32 itself is expressed specifically in benign prostate tissue, its two relatives, PP32r1 and PP32r2, are expressed in prostate cancer. The latter two are tumorigenic when stably expressed in NIH 3T3 cells, and the switch in expression from 'good' PP32 to its 'less salubrious' relatives might modulate the oncogenic potential of prostate cells.

Genetic Medicine at JHU_all under one roof

Nine of the existing centres and programs at the Johns Hopkins School of Medicine will be united under the roof of a new institute, the McKusickNathans Institute of Genetic Medicine. The name of the institute honours two faculty members: Victor McKusick, a cardiologist, a pioneer in the study of human inherited disorders and the creator of the internationally renowned Online Mendelian Inheritance in Man (OMIM) database, and Daniel Nathans, a research scientist awarded the Nobel Prize in 1978 (together with Hopkins colleagues Hamilton Smith) for the discovery that restriction enzymes could be used as molecular 'scissors' in the analysis of DNA. "The linking of the names of a clinical and a basic researcher reflects the character of the Institute in that it aims to bridge the gap between the research bench and the clinical bedside", according to Bart Chernow, acting director of the Institute. The Institute will embrace the tripartite mission of the Hopkins School of Medicine: the generation of new knowledge (through basic research), the sharing of knowledge (through training programs) and using this knowledge in clinical care (through clinical and diagnostic projects). Construction of the institute will break ground in 15 months and hopefully be completed within three years; a Director will be appointed within a year. By bringing genetic research programs spread throughout Hopkins under a single institutional umbrella and consolidating a budget worth tens of millions of dollars, Chernow believes that the Institute will provide the necessary critical mass of resources to enable research initiatives to push forward into large-scale genomic endeavours.

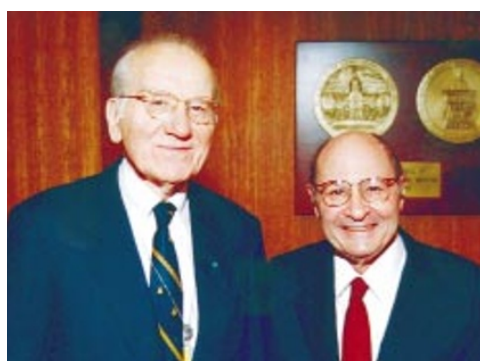

New genetic medicine institute at Johns Hopkins named in honour of Victor McKusick (left) and Daniel Nathans.

Of all God's creatures there is only one that cannot be made the slave of the leash. That one is the cat. If man could be crossed with the cat it would improve man, but it would deteriorate the cat.

-Mark Twain 